\title{
HISTORIA, FOLLETÍN E IDEOLOGÍA EN LOS MISTERIOS DEL PLATA DE JUANA MANSO
}

El impacto causado por Los misterios de París, la célebre novela de Eugenio Sue publicada entre 1841 y $1843^{1}$, no se agota por cierto en su país, sino que trasciende fronteras y llega hasta el lejano Río de la Plata ${ }^{2}$ al ritmo de los barcos que acercan los números del Journal des Débats a sus fervorosos lectores americanos.

Apenas una década después aparecerá en un semanario brasileño un folletín que invoca el magnetismo de aquel nombre para trasplantarlo a una realidad hispanoamericana: Los misterios del Plata, de Juana Manso de Noronha, una exiliada argentina que hace con esta obra sus primeras armas en la ficción. Y la novela que sale de su pluma es un panfleto contra el tirano Rosas, que ha empujado al destierro a una parte de la burguesía ilustrada de Buenos Aires, entre la cual se cuenta su propia familia.

Obra de una escritora novel, muy lejos de la complejidad de los mundos y submundos del modelo francés y de su magistral uso del suspenso, la originalidad -y los méritos- de la novela de Manso radican más en el desafío de la empresa que se propone que en sus resultados, un rasgo que caracterizará buena parte de su producción.

${ }^{1}$ El trabajo de Umberto Eco, "Eugenio Sue: el socialismo y el consuelo", El superhombre de masas. Retórica e ideología en la novela popular, $2^{\mathrm{a}}$ ed., Lumen, Barcelona, 1998, basado en la biografía de Sue por Bary, de 1962, ofrece variados testimonios de las múltiples respuestas que provocó entre los lectores franceses la publicación del folletín.

${ }^{2}$ Por su parte, Domingo F. Sarmiento documenta el fervor con que sus amigas de Santiago de Chile siguen el folletín, y que por cierto él comparte sin problemas; la posterior identificación entre "folletín" y "lecturas para mujeres" no es en absoluto constitutiva del género. Cf. carta desde París, Viajes, Hachette, Buenos Aires, 1955, t. 1, p. 207. 
Algo más que “la maestra amiga de Sarmiento”

La figura de doña Juana Paula Manso de Noronha ocupa un lugar destacado y polémico entre "el corto número de nuestras celebridades femeninas en la carrera literaria”, tal como la encuadraba, en 1853, el editor de La Ilustración Argentina ${ }^{3}$. Amiga y colaboradora de Sarmiento, su labor docente fue, durante mucho tiempo, lo que concentró la atención de los estudio$\operatorname{sos}^{4}$, ya sea en sus intentos de innovación de las escuelas primarias, ya en su larga tarea como directora de los Anales de la Educación Común creados en 1858 por el político sanjuanino.

Paralelamente, su producción literaria se vio relegada, y fue objeto de juicios lapidarios que la desterraron por décadas del canon nacional. Ricardo Rojas le dedica un breve párrafo en el capítulo "Mujeres escritoras" de su Historia de la literatura argentina, publicada entre 1917 y 1922. La pluma de don Ricardo, generalmente ecuánime y amable, se vuelve venenosa al trazar un retrato que perduró en el tiempo:

De Juana Manso (luego de Noronha, por su apellido conyugal) sólo diré que fue muy amiga de Sarmiento, a quien se parecía por su cara hombruna y por sus aficiones pedagógicas. La Sra. Manso ejerció la enseñanza en la Capital y en provincias; residió algún tiempo en Montevideo; fue periodista; publicó varios textos escolares, y compuso un drama histórico en cinco actos, La revolución de Mayo (1864), tema que veinte años antes había sido dramatizado por Alberdi. Los trabajos literarios de esta señora, muy estimados en su época, han vivido menos que su nombre 5 .

Si bien la labor de Manso nunca cayó del todo en el olvido, particularmente en lo que respecta a su producción sobre temas pedagógicos, es su obra literaria la que ha despertado recientemente un renovado interés, tanto en su producción periodística como ficcional. Diversas investigaciones han destacado la originalidad de una obra donde resuenan y se entrecruzan los ecos de un

${ }^{3}$ La Ilustración Argentina, 13-12-1853, núm. 2, p. 26.

4 Entre otros, Víctor Mercante, "Juana Manso", Revista de Educación, La Plata, 1930, núm. 13; MANON GuagliAnONE, Juana Manso. Una vida al servicio de la cultura argentina, Buenos Aires, 1968; María Velasco y ArIas, Juana Paula Manso. Vida y acción, Buenos Aires, 1937; Mercedes de la Vega, La maestra histórica, Buenos Aires, 1937.

${ }^{5}$ Ricardo Rojas, La literatura argentina, t. 2: Los modernos, 2a ed., Librería La Facultad, Buenos Aires, 1925, p. 792. 
período dramático de la historia argentina -el gobierno de Rosas y los años que sucedieron inmediatamente a su caída-así como la labor pionera y perseverante de esta escritora y fundadora de semanarios dedicados a la mujer y la educación ${ }^{6}$.

Juana Manso publicó solamente dos novelas: Los misterios del Plata $\left(1852^{7}\right)$ y La familia del comendador (1854), aunque, según declaraba al terminar la primera, se había propuesto un plan formado por una serie de relatos históricos ${ }^{8}$. Los misterios tuvo varias ediciones (además de una segunda versión) posiblemente por el interés del asunto, inserto en la abundante literatura que suscitó la figura del "Restaurador de las Leyes". La segunda, de ambiente y tema brasileño, no tuvo reediciones, y es de muy difícil acceso ${ }^{9}$.

${ }^{6}$ Destacamos aquí los estudios de Lelia Area, "El periódico Álbum de senoritas de Juana Manso (1854): una voz doméstica en la fundación de una nación”, RevIb, 63 (1997), núms. 178/179; Mujeres y cultura en la Argentina del siglo XIX, coord. Lea Fletcher, Buenos Aires, 1994; LiLiana Zucotti, "Gorriti, Manso: de las Veladas literarias a «Las conferencias de maestra»", en Mujeres y cultura..., y "Los misterios del Plata: el fracaso de una escritura pública”, Revista Interamericana de Bibliografía, 45 (1995), núm. 3, 381-389, que resolvió numerosas dudas en nuestro primer acercamiento a la obra de Manso; GABriela Mizraje, Argentinas de Rosas a Perón, Biblos, Buenos Aires, 1998, cuyo estudio es de consulta indispensable, lo mismo que los que dedica a otras escritoras argentinas; y el más reciente de Lidia F. Lewkowicz, Juana Manso (1819-1875). Una mujer del siglo XXI, Corregidor, Buenos Aires, 2000, cuyas consultas hemerográficas en bibliotecas de Río de Janeiro y Montevideo aportan valiosos datos sobre las ediciones originales, así como sobre la actividad de Juana Manso durante su exilio. La obra de María Velasco y Arias (cit. supra, n. 4) es, según ella misma afirma, la primera biografía y estudio sobre la escritora, y ofrece valiosa documentación inédita, pero también contiene unos cuantos errores que después repitió la crítica. Por otro lado, contribuyó a instalar el aura hagiográfica que se encuentra en muchos de los trabajos sobre la escritora.

${ }^{7}$ Cito por Los misterios del Plata. Episodios históricos de la época de Rosas escritos en 1846, ed. prologada y corregida por D. Ricardo Isidro López Muñiz, Librería de Jesús Menéndez, Buenos Aires, 1924. (Puede consultarse en internet en el sitio de la Biblioteca Virtual Cervantes.) En adelante, LMP. En varios trabajos citados en la bibliografía se da 1850 para la primera edición. La investigación de LEwKOwICz, que consultó el original brasileño, modifica esta fecha, con las consecuencias que luego se verán sobre el lugar que ocupa la novela en la producción de la época.

8 "Os Mysterios del Plata nao sao mais do que o começo de uma serie de romances historicos que apparecerao mais tarde, se me for possivel darlhes publicidade" (Jornal, 2-6-1852; citado en LewKowicz, op. cit., p. 217).

${ }^{9} \mathrm{La}$ autora homenajea en esta obra a una de las patrias de su exilio: "Siempre que hable de ti, Brasil, lo haré con entusiasmo, porque has sido 
Los misterios del Plata ocupa un lugar particular dentro de la literatura antirrosista por varias razones: escrita por una mujer en el exilio, la historia - a diferencia de los demás relatos de este corpus, donde el terror omnipresente se inviste de diversas formas para desembocar en un ineludible destino trágicoconcluye con un "final feliz" que se convierte en augurio de un futuro de triunfo, dotado de una clara intención ideológica.

\section{UNA VIDA AGITADA}

Juana Paula Manso nació en Buenos Aires en $1819^{10}$, hija de un ingeniero agrimensor andaluz, don José María Manso, y de una porteña, Teodora Cuenca. Lectora temprana y ávida ("aprendí a leer por mí misma, preguntando una letra y otra, combinando los sonidos, a los seis años de edad", le escribirá a Sarmiento $^{11}$ ) devoró en su adolescencia folletines como Isabel o los desterrados de Siberia "no sin regar con lágrimas sus páginas" y hace sus "primeras armas en la literatura con dos traducciones del francés, una a los 13 y otra a los 14 años" ("El egoísmo y la amistad o Los defectos del orgullo", 1833, y "Mabrogenia o la Heroína de la Grecia", 1834), que su padre manda imprimir.

En 1836, ya instalado Rosas con la suma del poder público, el ingeniero Manso emigra a Montevideo, sede de la oposición unitaria. Allí ejerce su profesión delineando la nueva planta de la ciudad y "la calle sobre el agua [?] que se consideró una nueva locura de Manso", como recordará más tarde Juana con orgullo filial ${ }^{12}$.

En 1840, agravada la situación política en Buenos Aires tras el asesinato de Manuel Maza, presidente de la Cámara de Representantes $^{13}$, la familia completa se traslada a Montevideo. Allí Juana abre una escuela (el Ateneo de Señoritas), se vincula con los jóvenes de la Generación del 37 -entre ellos Echeve-

por muchos años mi patria adoptiva, y estás ligada a mi corazón y a mi pensamiento por un altar y dos tumbas. El altar en que ligué mi destino al destino de otro, las tumbas de mi anciano padre muerto en la emigración y la de mi primer hijo, muerto antes de nacer" (citado en Lewkowicz, op. cit., p. 249).

${ }^{10} \mathrm{Si}$ bien hay algunas divergencias sobre la fecha-MERCANTE (art. cit.), la sitúa en 1820- ésta suele ser la más aceptada por los biógrafos.

${ }^{11}$ Apud V. Mercante, art. cit., p. 80.

${ }^{12}$ J. Manso, "Pájinas del alma", Revista Argentina, 5 (1869), p. 132.

${ }^{13}$ El episodio se ficcionaliza en la novela de Manso. 
rría, a quien, según confiesa, admiraba como poeta pero que la defraudará por su aspecto físico poco agraciado ${ }^{14}$, y José Mármol, con quien entabla una amistad literaria-, e inicia la publicación de sus primeros poemas en diversos periódicos.

En 1842, el sitio de Oribe - aliado de Rosas- sobre Montevideo impulsa a los unitarios a un nuevo exilio, esta vez en Río de Janeiro. Allí conoce Juana al violinista portugués Francisco de Saa Noronha, con quien se casa en 1844. En abril de 1846 desembarcan en los Estados Unidos, llevados por la promesa de éxito con que "el cónsul americano en Pernambuco nos había trastornado el juicio...; y nosotros, con esa confiada imprudencia de la mocedad inexperta, nos arrojamos con escasos medios a probar fortuna en país tan extraño y distante"15. Pero la programada gira artística se convierte en un fracaso total; en cambio, recibirán una calurosa recepción en Cuba, adonde llegan en 1848. En sus "Recuerdos de viage", Juana evocará las fiestas de San Juan, que durante una semana alborotan a la isla en un "frenesí" de "máscaras, bailes, serenatas y chascos", los paseos en quitrín ("cada uno con una chiquilla en las faldas"16) y los sonidos de la banda que, al reconocer al músico, hacen oír en su homenaje las contradanzas que creara imitando a las cubanas ("La Principeña" y " La Paula") ${ }^{17}$.

De regreso a Río colabora con su esposo en la creación de dos zarzuelas, "Elvira la Saboyarda" y "Esmeralda"18. Poco después publica su primer semanario, el Jornal das Senhoras. Modas, Litteratura, Bellas-Artes, Theatros e Critica, donde aparecerá como folletín Mysterios del Plata.

Abandonada por su marido, que se vuelve a Portugal, Juana emprende el regreso a Buenos Aires en julio de 1853 con sus dos hijas pequeñas, siguiendo el camino de todos los exiliados

${ }^{14}$ Lo recuerda medio bizco y picado de viruelas; $\mathrm{cf}$. L. F. Lewkowicz, op. cit., pp. 94-97.

15 Así recordará Juana esta "aventura", en un relato dirigido a su hija mayor y que se mantuvo inédito; Velasco y Arias (op. cit.) reproduce pasajes de ese cuaderno, que pudo consultar para su obra. La negativa imagen del país que se ofrece en el texto recuerda la amarga sátira de Dickens, después de su viaje en 1842.

${ }^{16}$ En Estados Unidos había nacido su hija Eulalia; en Cuba nace la segunda, Erminia. p. 54.

${ }^{17}$ J. Manso, "Recuerdos de viage", La Ilustración Argentina, 1854, núm. 4,

18 L. F. Lewkowicz, op. cit., p. 50. 
que más tarde o más temprano, vuelven a la patria tras la caída de $\operatorname{Rosas}^{19}$. La ciudad a la que regresa ha vivido una serie de acontecimientos que marcarán por largos años el destino del país. El general Urquiza, vencedor de Rosas, no es visto con buenos ojos por los antiguos exiliados, que desconfían de ese gaucho entrerriano poco dispuesto a otorgar a Buenos Aires la supremacía que reclama la Provincia, así como tampoco a ejercer las venganzas que se tramaron durante los largos años del destierro. La prensa porteña se convierte en vocero de la campaña antiurquicista. Más aún, un grupo de jóvenes, acaudillado por Adolfo Alsina (el "niño Adolfo" de la novela) trama un complot para asesinarlo que no llega a concretarse ${ }^{20}$.

La unión de las fuerzas hostiles a Urquiza desemboca en una revolución, en el mes de septiembre de 1852, que, apelando a todos los recursos - entre ellos, el soborno al jefe de la flota nacional, el almirante norteamericano Cole- termina por desmembrar al país: por un lado, la Confederación presidida por Urquiza; por el otro, el gobierno independiente de Buenos Aires, al mando de Valentín Alsina. La figura del general Mitre va cobrando perfiles de jefe indiscutido, y se convertirá durante varias décadas en uno de los principales gestores de la política nacional.

Terminado el período conciliador de Urquiza, el triunfo de los porteños abre el tiempo de la revancha. Se confiscan los bienes del "tirano", que vivirá un oscuro destierro en Inglaterra hasta su muerte en 1877, y se castiga duramente a sus seguidores, los jefes de la Mazorca ${ }^{21}$, ejecutados en la Plaza de Mayo

${ }^{19}$ La familia Alsina (protagonista de Los misterios) es de las primeras en volver: Rosas es derrotado en la batalla de Caseros el 3 de febrero de 1852; el 8 ya están los Alsina en Buenos Aires, donde ocuparán importantes espacios en la política. Mármol regresará definitivamente a comienzos de 1854, recibido con los aplausos que se merece "una de las más altas reputaciones de la República Argentina” (La Ilustración Argentina, 12-2-1854, núm. 10).

${ }^{20}$ Jacinto Yaben, Biografías argentinas y sudamericanas, Metrópolis, Buenos Aires, 1938, p. 119.

21 La Sociedad Popular Restauradora, más conocida como la Mazorca (Más-horca, según alguna de sus etimologías), fue una fuerza de choque organizada entre los seguidores de Rosas, primero para lograr su regreso al poder, y después para hostilizar a sus opositores, llegando en muchos casos a bárbaras ejecuciones. Rosas la disolvió en 1846, incorporando a sus miembros a las milicias. La "sombra terrible" de la Mazorca cobra una dimensión mítica en las crónicas, memorias y novelas que reflejan la época. Las cifras de las muertes causadas no siguen ninguna estadística científica, sino que 
como castigo público y ejemplo para las generaciones venideras. Los periódicos porteños transmiten el mensaje que llega desde el gobierno: "La presente semana dio principio con un acto de aquellos que harán época en la historia de este pueblo... Con la ejecución de los criminales [los mazorqueros Troncoso y Badía] se hizo un acto de justicia hacia la agraviada sociedad"22.

En este contexto no hay lugar para la discusión racional o la búsqueda de consenso. Los periódicos que propugnan el inicio de una etapa de unidad y conciliación son prontamente acalla$\mathrm{dos}^{23}$. En cambio, las personas que desde el exilio manifestaron abiertamente su oposición a Rosas encuentran todos los espacios francos para su reinserción en esta nueva etapa. Es el caso de Juana Manso, cuyo regreso se anuncia en términos laudatorios:

De vuelta a su país natal después de un largo viage por Europa, empieza ahora a rendir a su patria los frutos de su inteligencia, como en otra hora los ofrecía desde suelo estraño, adonde la llevaron las vicisitudes políticas y su noble corazón por no presenciar de cerca la degradación en que yacía sumida nuestra madre común. Nos felicitamos, como porteños, de la adquisición que hacemos de la señora Manso de Noronha ${ }^{24}$.

Y será, años más tarde, el caso de Juana Manuela Gorriti, cuya visita casi póstuma a doña Juana Paula tiene sentido de homenaje: "Apenas llegó a Buenos Aires Manuela Gorriti, ya gloriosa -me refería Vega Belgrano-, fue a casa de Juana Manso y, poniéndose de rodillas, la dijo, conmovida: ¡salve, maestra!”25.

obedecen exclusivamente a objetivos políticos, ya sea de los amigos o de los enemigos del régimen rosista.

22 La Ilustración Argentina, 23-10-1853, núm. 7, sección Revista de la Semana. En diciembre serán ejecutados los mazorqueros Cuitiño y Alen; el castigo ejemplar se verá reforzado por la presencia de los familiares de las víctimas.

${ }^{23}$ Así ocurre con La Ilustración Argentina, cuyos editores son desterrados.

24 La Ilustración Argentina, 13-12-1853, núm. 2. En su afán por exaltar la figura de la escritora, el editor exagera la dimensión de los viajes de doña Juana, que visitó los Estados Unidos, las Antillas, Brasil y Uruguay, pero no llegó hasta Europa.

25 V. Mercante, art. cit., p. 82. Gorriti hace su primer viaje a Buenos Aires a comienzos de 1875; Manso muere en abril de ese mismo año. 
En Buenos Aires reinicia Juana su labor literaria. El $1^{\circ}$ de enero de 1854 aparece su revista Álbum de Señoritas ${ }^{26}$, donde emprende la reedición de La familia del comendador. En la misma línea de actualización y traducción de sus trabajos anteriores, varios artículos suyos se reeditan en publicaciones porteñas ${ }^{27}$; una manera de arraigarse nuevamente en la tierra natal, vinculando su presente con su pasado de escritora o, como se definirá ella misma, de "femme auteur, como dirían los franceses"28. Paralelamente retoma su tarea como educadora, y colabora con Sarmiento en la dirección de escuelas y en la edición de revistas pedagógicas ${ }^{29}$.

En la política argentina se han enfrentado los antiguos aliados contra Rosas, Bartolomé Mitre y Adolfo Alsina, los dos jóvenes que regresaran del exilio con un definido proyecto político. El segundo crea el Partido Autonomista, al cual se vincula Manso en 1859. Ello no es obstáculo para que dedique a Mitre, en términos agradecidos y encomiásticos, su Compendio de historia de las Provincias Unidas del Río de la Plata..., que el general recibe con complacencia, aunque sin dedicarle demasiada atención. Escribe Manso al "poeta historiador Mitre"30:

Debo a V. esclusivamente mi regreso al Río de la Plata; y le debo, de igual manera, la cooperación más franca y amistosa para formarme la posición que hoy ocupo en mi país natal.

Así es que, el primer fruto de ese bienestar moral que solo puede producir el aire patrio, y una vida laboriosa y tranquila, he querido consagrárselo; y ligar a este humilde libro, destinado a ser leído por centenares de generaciones, el suave recuerdo de

${ }^{26}$ Para el estudio de esta publicación nos remitimos al trabajo ya citado de Lelia Area.

27 Por ejemplo, sus "Recuerdos de viage", publicados en La Prensa de Rio Grande, aparecen nuevamente en La Ilustración Argentina (1854) "refundidos por su autora". Su artículo, "La emancipación moral de la mujer", había sido reeditado en la misma publicación en 1853.

28 "Quem eu sou e os meus propositos", en Jornal das Senhoras, 11-11852; reproducido en LewKowicz, op. cit., p. 96.

${ }^{29}$ En este trabajo nos interesa la figura de Manso como escritora; para su faceta docente, nos remitimos a los trabajos ya citados en nota 4 .

30 Compendio de la historia de las Provincias Unidas del Río de la Plata desde su descubrimiento hasta el año 1874, $9^{a}$ ed. notablemente corregida en que se ha extendido la historia hasta el año de 1881, Ángel Estrada, Buenos Aires, s/f [¿1882?]. Así reza la dedicatoria manuscrita del volumen que se conserva en la Biblioteca del Museo Mitre. 
una noble acción que revela en $\mathrm{V}$. un corazón benéfico y sus generosos sentimientos.

Y le contesta el general, el 15 de abril de 1862:

Señora mía y amiga: Devuelvo a V. los cuadernos relativos a la historia del Río de la Plata... Habría deseado contraerme más al examen de la obra, para poder enviar algunas observaciones; pero me ha faltado el tiempo para ello ${ }^{31}$.

En 1864 Juana Manso crea con Eduarda Mansilla ${ }^{32}$ la revista La Flor del Aire. Periódico literario ilustrado dedicado al bello sexo, que dura poco más de un mes. Enseguida funda, esta vez sola, $L a$ Siempreviva, que tampoco tiene larga existencia. Simultáneamente colabora en publicaciones como la Revista Argentina, dirigida por José Manuel Estrada, o La Ilustración Argentina, de Benito Hortelano.

A poco de iniciada la guerra contra el Paraguay se crea en Buenos Aires el periódico El Inválido Argentino, bajo la dirección de Juan María Gutiérrez. Allí inicia Manso una nueva versión de Los misterios bajo el título Guerras civiles del Río de la Plata.

Continúa su tarea docente y su labor militante junto a Sarmiento, afrontando la hostilidad que despertaban sus medidas de renovación pedagógica, inspiradas en buena medida en los modelos norteamericanos que admirara durante su viaje a Estados Unidos y que fueran firmemente propugnados en la Argentina por su maestro.

El 24 de abril de 1875 muere de hidropesía en Buenos Aires. Años antes se había convertido al protestantismo, por lo cual se le niega sepultura en el cementerio católico de la Recoleta y es enterrada en el Británico.

31 J. Manso, Compendio de la historia de las Provincias Unidas del Río de la Plata desde su descubrimiento hasta la declaración de su Independencia el 9 de Julio de 1816. Destinado para el uso de las escuelas de la República Argentina, Imp. y Lit. a vapor de Bernheim y Boneo, Buenos Aires, 1862.

${ }^{32}$ Eduarda Mansilla era hija de Agustina Rosas, la hermana predilecta del Restaurador. Con Manso, Gorriti, María S. de Thompson, Rosa Guerra y Mercedes Rosas forman parte del grupo de "celebridades literarias" a las que aludía La Ilustración Argentina hacia 1853 (cf. nota 3). 


\section{La sombra del modelo}

"Comecei a esboçar este romance en Philadelphia, em 1846; foi concluido na fortaleza do Garavatá, onde morei cinco mezes, em fins de 1849 e principios de 1850", confiesa la autora al culminar la publicación de su novela en el Jornal das Senhoras, el 2 de junio de $1852^{33}$.

Esta temprana lectora de folletines no ha quedado ajena al impacto causado por la obra de Sue. En alguna ocasión, durante su viaje a Estados Unidos, intercambia con una dama de Filadelfia sus entusiasmos por los autores predilectos: "Hablamos de arte, de literatura, de Eugene Sue, de Dumas, de Jorge Sand" 34 . El comentario revela la atención con que estas lectoras americanas siguen los éxitos más recientes de la novela europea. Con respecto al más admirado de los folletinistas del momento, Eugenio Sue, cabe recordar el comentario de Belinski sobre su difusión en toda Europa:

¿Vale la pena decir que esta novela, o mejor estas Mily una noches europeas, que un periódico publicaba por entregas, cautivó al público de París, y por consiguiente, al público de todos los países del mundo donde se recibían los periódicos franceses (¿y dónde no se recibian?); o que así que aparecieron los volúmenes se agotaron, leídos y releídos, ensuciados y manoseados en todos los puntos del globo donde se hablaba francés (¿y dónde no se hablaba?); que se tradujo a todas las lenguas de Europa... e hizo nacer un gran deseo por imitarla? 35

Entre sus numerosos lectores americanos, tal vez el que exprese con mayor fervor su adhesión sea Sarmiento, quien, en su viaje iniciático a París, se esforzará, apenas pisado el pavimento parisiense, por localizar los escenarios de los personajes de la ficción, en esa peregrinación literaria que todo lector leal alguna vez ha realizado. Antes de iniciar la misión que le ha encomendado el gobierno chileno y de ponerse en contacto con

33 Apud L. F. LewKowicz, op. cit., p. 217.

34 Apud Velasco y Arias, op. cit., p. 248.

35 V. Belinski, "Los misterios de París" [1842-1845], en U. Eco, E. A. Poe et al., Socialismo y consolación. Reflexiones en torno a "Los misterios de París", Tusquets, Barcelona, 1980; las cursivas son mías; el comentario corresponde a 1844 . 
las primeras figuras de la política -Thiers, Guizot-Sarmiento se dedica a recorrer París en busca de "las covachas y vericuetos donde los Misterios comienzan" 36 . Por su parte, por esas mismas fechas Juana Manso, durante su viaje a Estados Unidos, empieza a pensar en el ámbito de la ficción para revelar los "dramas espantosos" ( $L M P$, p. 7$)$ que se desarrollan en la patria lejana y elige, como marco y como homenaje (¿como garantía de atracción para los lectores, también?) el modelo francés. No es la única en hacerlo. Los misterios de París abrieron camino a una serie de obras que, en vista del probado éxito de la fórmula folletinesca, la reprodujeron en otros ámbitos geográficos, aunque con menor fortuna que su modelo. Romero Tobar ${ }^{37}$ menciona Los misterios de Madrid (1844) de Martínez Villergas; Les mystères de Londres (1844), de Paul Feval; Les mystères du peuple, del mismo Sue (1849-1856); y cabría agregar, entre otros, Los misterios de la India, de Xavier de Montepin y los Misterios argentinos, de Manuel Olascoaga (ca. 1865) ${ }^{38}$.

A pesar del título, la novela de Manso se encuentra, como ya señalamos, bastante distante del folletín de Sue. En realidad, como la misma escritora declara en sus palabras iniciales - para sorpresa del lector- no pretende apegarse a él: "Al poner a esta obra el título de «MISTERIOS DEL PLATA», no es mi ánimo imitar los Misterios de París de Eugenio Sué [sic]; ni hacer otros Misterios de Londres" (LMP, p. 7).

En la novela de Sue los "misterios" giran en torno a los tópicos que caracterizan el folletín: cambios de identidad, secuestros, venganzas, castigos justicieros, muertes aparentes, reconocimiento de hijos, etc.; y la intención del autor, que se irá profundizando ${ }^{39}$, es denunciar la situación miserable de las clases trabajadoras de París. En el texto de Manso, en cambio, el objetivo es político y partidista: el misterio a develar ante "los ojos del mundo civilizado" es la situación de su país, teatro de "dramas espantosos" desde "ha ya tantos años". Y su propósito es

36 Pero la nueva traza urbana ha borrado -se lamenta- esos escenarios. Cf. carta desde París a su amigo Antonino Aberastain, el 4 de septiembre de 1846 (Domingo F. Sarmiento, Viajes, p. 207).

${ }^{37}$ La novela popular española del siglo XIX, Ariel, Madrid, 1976.

38 Cf. Fermín Chávez, Historicismo e iluminismo en la cultura argentina, CEAL, Buenos Aires, 1982.

${ }^{39}$ U. Eco (art. cit.) expone la conversión del dandy que era Sue al comenzar su actividad literaria en el diputado socialista que termina sus días en el exilio, tras el ascenso de Luis Napoleón. 
lograr que "el mundo entero sepa lo que los argentinos deben a ese Rosas, oprobio y vituperio de la humanidad entera" (p. 8).

Si bien resulta un tanto sorprendente, hay que señalar que esta libre adaptación del término misterio no es infrecuente en el mundo hispánico. Según Romero Tobar, en los misterios aparecidos a la sombra del modelo francés se presenta una "extraña mezcolanza de temas en la que aparecen reunidos algunos de los tópicos de la literatura popular tradicional con las cuestiones candentes de la política del momento". De tal manera, es la ficción la que proporciona las estructuras para la exposición de una realidad que se quiere denunciar y combatir.

Para los unitarios enemigos del régimen que los mantiene lejos de su patria y del poder, la larga permanencia de Rosas en el gobierno -ya lleva 17 años al iniciarse la redacción de la novela, y todavía estará seis años más ${ }^{40}$ - se presenta como un fenómeno incomprensible que requiere ser estudiado con herramientas que trasciendan el análisis político, a todas luces insuficiente, a juzgar por los hechos. ¿Cómo puede un tirano sanguinario, brutal, de costumbres rurales y atrasadas, mantenerse en el poder a pesar de las sucesivas guerras internas y externas? ¿Qué fuerzas lo sustentan? ¿Qué clase de sociedad es ésta que lo tiene como caudillo y amo?

En un texto contemporáneo de Los misterios, Sarmiento parte de una concepción análoga al inclinarse sobre la compleja realidad que intenta analizar en su Facundo ${ }^{41}$ : los males que aquejan a la República Argentina. Hay que indagar en la vida secreta de un pueblo para encontrar las razones de sus luchas internas, de su alejamiento de los caminos que deberían conducirlo hacia el progreso y la civilización, de acuerdo con el pensamiento de la Generación de 1837. En la interpretación de Sarmiento, lo secreto, lo misterioso y oscuro va unido a lo sobrenatural. Por ello se evoca la "sombra terrible" de un muerto para que explique lo que la razón no ha logrado esclarecer: "Tú posees el secreto: ¡revélanoslo!" reclama a Facundo Quiroga, el caudillo asesinado en la lucha entre facciones.

En las páginas preliminares de su novela, Juana Manso declara su propósito: mostrar los "misterios negros como el abis-

${ }^{40}$ Recordemos que el gobierno de Rosas se extiende, con un breve período intermedio, entre los años 1829 y 1852, cuando es derrocado por Urquiza, con el apoyo del ejército del Imperio del Brasil.

${ }^{41}$ Domingo F. Sarmiento, Facundo. Civilización y barbarie, Editora Nacional, Madrid, [1875] 1975. 
mo" que tiene como escenario "esta desventurada tierra" (del Río de la Plata); y en torno a este objetivo organiza su estrategia narrativa. Los resultados no son los mejores en el plano literario. La novela está llena de personajes y escenas previsibles; deja cabos sueltos (la relación entre Ramón Maza, medio hermano de Adelaida, y su novia, por ejemplo); se superponen historias débilmente vinculadas con la trama central -el juicio por uxoricidio del coronel Rojas, un personaje secundario-; y concluye con un desenlace precipitado, que, según aclara la nota del editor, es un agregado posterior ${ }^{42}$.

\section{Un texto problemático}

Establecer el texto de la novela presenta una serie de dificultades, ya que nunca se publicó completo en vida de la autora y la versión definitiva (1899) fue corregida, completada y enmendada por el editor.

La edición que utilizamos es la de 1924, que se basa en la de 1899, publicada un cuarto de siglo después de la muerte de la autora. Lleva como subtítulo "Episodios históricos de la época de Rosas escritos en 1846” y tiene un prólogo de Ricardo López Muñiz. Le sigue una advertencia preliminar -"Una palabra sobre este libro"-donde Manso expone sus objetivos, a la vez que señala la situación de enunciación: lejanía geográfica respecto a "aquella desventurada tierra" sobre la cual escribe, pero contemporánea con los hechos desarrollados bajo el gobierno del "hombre tigre - conocido hoy con el nombre de Juan Manuel de Rosas" (LMP, p. 7, las cursivas son mías).

A la espera de una edición definitiva que aclare los problemas que aún siguen pendientes sobre el texto, es posible trazar el recorrido de las diversas versiones y ediciones.

La edición de 1852. La novela, escrita en el exilio entre los años 1846 y 1850, según testimonio de la autora, se publica en portugués como folletín en el Jornal das Senhoras entre el 4 de enero y el 2 de junio de 1852. Es decir, la mayor parte de la publicación aparece tras la caída de Rosas, derrotado en Caseros el 3 de fe-

42 "La persona que ha suministrado los datos necesarios al editor de esta obra para terminarla, prepara un folleto relatando este episodio histórico [la fuga de Alsina]" (nota, p. 213). 
brero. Sin embargo, en el último número del folletín, Manso manifiesta su temor a publicar estos secretos, que Rosas seguramente no le perdonaría. Y agrega esta extraña observación:

O epilogo do presente romance nao é possivel por ora publicar-se no Jornal das Senhoras por inconvenientes independentes da nossa voutade, mas estamos disposta, sempre que acharmos cooperaçao, a fazer uma ediçao dos Mysterios acompanhada entao do epilogo 43 .

¿A qué se debe la eliminación del epílogo? No resulta convincente una autocensura motivada por los resabios de temor hacia un Rosas derrotado y fugitivo; más aún, cuando ofrece incorporarlo de inmediato a la eventual edición en libro -algo habitual con los folletines que habían obtenido el suficiente favor del público, pero que no sucede esta vez.

La autora tiene muy presente a su destinatario, el lector brasileño, ajeno a los ires y venires de la historia rioplatense, a su lenguaje y a sus costumbres. De allí las aclaraciones a nivel de léxico, como cuando se explica que rancho "quiere decir una casa con las paredes hechas con algunos palos groseros cubiertos de barro y estiércol y el techo de paja" (p. 11). O cuando, al describir al presidente Oribe - figura aborrecida por los unitarios-se comparan "sus dientecitos blancos y agudos" con los de "los negros minas" (p. 39), una imagen mucho más evocadora para el lector brasileño, familiarizado con los negros esclavos, que para el rioplatense. O cuando se explica in extenso el proceso de fabricación de la "bota de potro", donde el cuidado del gaucho deja el cuero "tan dócil y suave como cabritilla" (nota, p. 103).

También utiliza las extensas notas al pie -sobre las cuales llama expresamente la atención del lector en su prólogo-para presentar episodios o figuras relevantes del gobierno de Rosas, como los hermanos Reinafé, presuntos asesinos de Facundo Quiroga, o el litógrafo francés Bacle, encarcelado por Rosas bajo sospecha de espionaje (pp. 72-73). Estas notas sirven al propósito militante de la escritora, que interpreta los hechos -sin preocuparse por la veracidad de las fuentes-de acuerdo con la intención de toda la obra. Así, cuando menciona al mazorquero Cuitiño, la nota al pie agrega una observación tendenciosa: "Cuitiño fue enviado enfermo a Tucumán hace dos años, se

43 Citado por Lewkowicz, op. cit., p. 217. 
cree envenenado por Rosas (1846). La Autora" (p. 133). De hecho, al comandante Cuitiño le tocaría vivir unos cuantos años más, hasta ser fusilado y colgado en la Plaza de Mayo tras la caída de Rosas, el 29 de diciembre de 1853. Manso ya estaba de regreso en Buenos Aires, y puede haber seguido atentamente, como toda la población, el debate en torno a la culpabilidad de los $\operatorname{reos}^{44}$.

La edición de 1867. En el transcurso de la guerra contra el Paraguay, el periódico El Inválido Argentino empieza a publicar como folletín una versión revisada - y mejorada- de los Misterios, bajo el título Guerras civiles del Río de la Plata. Primera Parte. Una mujer heroica. 1838 y firmada con el seudónimo de "Violeta". Esta versión abandona el "aura" del modelo francés para elegir un título más acorde con el perfil docente y académico de quien acababa de publicar el Compendio de historia de las Provincias Unidas. A la vez, desde el título se destaca la figura de una "mujer heroica", focalizando la atención de lector hacia uno de los ejes de significación de la novela, y en el cual algunos han querido ver una suerte de autohomenaje. La estructura prevista para esta nueva versión se expone al presentar el folletín, el 29 de diciembre de 1867:

Las guerras civiles del Río de la Plata constarán de dos partes: la primera, sin nombres propios, será el romance de una mujer que ya no existe pero que aún tiene próximos deudos, y que será fácilmente reconocida; la segunda parte se denominará "Páginas de la juventud" y contendrá más de un nombre propio, como crónica social de los incidentes de una época política separada de nosotros por el lapso de 28 años $^{45}$.

La novela no llega a completarse tampoco esta vez - la vida del Inválido no fue muy prolongada- lo cual es de lamentar ya que esta versión ofrece, por un lado, mayor objetividad históri-

${ }^{44}$ En El Plata Científico y Literario, el abogado Marcelino Ugarte expondrá su defensa de los mazorqueros Ciriaco Cuitiño y Leandro Alen, justificándolos con base en una argumentación del tipo "obediencia debida" que en esa época no tuvo efectos favorables sobre los jueces (t. 1, 12-6-1854).

45 J. Manso, "Guerras civiles del Río de la Plata. Primera parte. Una mujer heroica. 1838”, El Inválido Argentino, Buenos Aires, 29-12-1867, núm. 53, y 2-2-1868, núm. 60. 
ca, y por otro, revela mayor oficio literario en la escritora. Abundan las digresiones que comparan el pasado con el presente en cuanto a las transformaciones urbanas, dentro de la línea costumbrista, se utiliza el humor al retratar ciertos cuadros característicos, y en general se ha aligerado el tono docente o excesivamente panfletario ${ }^{46}$. El Inválido dejó de aparecer al estallar la epidemia de fiebre amarilla en Buenos Aires; pero al cesar ésta no volvió a publicarse, ni Manso a buscar un nuevo espacio para completar su novela -como sí lo hizo Mármol con Amalia (1851-1855). De alguna manera, la autora parecería estar ahora más ligada con la tarea docente que con sus entes de ficción, que quedan atrás, como si pertenecieran a una etapa ya cerrada de la juventud. Así se desprende de una carta a Sarmiento, donde le da cuenta de su actividad proselitista a favor de su candidatura presidencial, y agrega como al pasar: "Y para atenuar el hastío que suele visitarme en la inacción a que me reduce la costumbre, por pasatiempo reproduzco en folletín una novelita original de los tiempos en que yo escribia dramas y novelas en Brasil por el año 52"47.

La edición de 1899. Se trata de la primera edición completa de la novela, con los agregados y correcciones del editor, Ricardo López Muñiz, explicitados en notas ${ }^{48}$ y casi siempre pertinentes -como cuando propone la fecha verdadera del episodio histórico que sirve de base a la ficción (p. 213). Sobre esta edición, que contiene la conclusión faltante en el folletín brasileño y que las hijas de Manso habrían supervisado ${ }^{49}$, se realizaron las siguientes.

46 Lamentablemente, en la Biblioteca Nacional de Buenos Aires sólo puede consultarse el primer tomo -donde aparecen los 14 primeros capítulos- que se cierra con el núm. 60, del 16 de febrero de 1868; el segundo volumen está tan deteriorado que no se presta al público.

47 Apud Velasco y Arias, op. cit., p. 329; las cursivas son mías.

48 "Hasta aquí llegó en su manuscrito la autora. Quedando trunca la obra, el editor la ha terminado, de acuerdo con las indicaciones de una persona competente y conocedora de nuestra historia nacional, a fin de conservar, en lo posible, el carácter de novela histórica que tiene este trabajo" (nota, p. 199).

49 Según Liliana Zucotti, las hijas de Manso se hicieron cargo de las obras éditas e inéditas de su madre. De hecho, tienen a su cargo la edición de 1881 del Compendio, que si bien no llegó al "centenar de generaciones de lectores”, como soñaba su autora, sí logró una considerable difusión, al amparo de Mitre y Sarmiento (nueve ediciones entre 1862 y 1881). 
Para continuar con los "misterios" que ofrece la obra, en esta edición difieren los datos de la portada y la portadilla interna. La portada, ilustrada con una escena difícilmente localizable en la novela, presenta como título Los misterios del Plata. Novela histórica escrita en 1846 por Juana P. Manso de Noronha, como editor a N. Tommasi y como fecha 1900. La portadilla, en cambio, localiza la edición en la Imprenta Los Mellizos, y en 1899.

Esta edición no trae índice y presenta varios descuidos (saltea numeración de capítulos, comete errores en la ubicación de las notas).

La edición de 1924. Esta edición, que es la que manejamos, se basa en la de 1899, con el subtítulo ligeramente modificado ${ }^{50}$; en ella se salvan los errores de la anterior y aparece una nueva mano: un corrector poco respetuoso de los severos juicios de la autora. Por ejemplo, al trazar el retrato de Juan Manuel de Rosas, dice Manso: "Su edad será de unos cincuenta y siete o cincuenta y ocho años [de hecho tenía 45 en 1838]. Sus cabellos rubios y sedosos empiezan a encanecer, porque así como la desgracia, el crimen ejerce sobre los individuos su temible influencia". El impertinente corrector se permite esta nota al pie: "Si el criminal encanece recién a los cincuenta y siete años, convengamos en que su influencia no es muy desastrosa" (pp. 109-110).

La edición de 1933. Está editada por J. C. Rovira, dentro de la Biblioteca "La tradición argentina", una colección destinada a un público popular, y por lo tanto, en función de la indiferencia que se presume en este tipo de lector hacia minucias más o menos académicas, se prescinde del aparato de notas y se deslizan varios descuidos y algunos errores. Se elimina la introducción de Manso, y el editor, en un breve prólogo que recoge algunas palabras de la autora, agrega de su cosecha cosas como ésta:

Juana Manso desgraciadamente falleció antes de que apareciera su obra y antes de ver a Rosas lejos del poder. La devoción de sus amigos no quiso que obra tan justiciera quedara a medias y fue así, gracias a ellos, que apareció la primera edición de este libro que es toda una patriótica acusación.

Explica estos errores o descuidos el tipo de colección que incorpora la obra: es una publicación semanal que ofrece en

50 "Episodios históricos de la época de Rosas escritos en 1846". 
otras colecciones títulos como Tarzán y la esfinge y La venganza amarilla. El editor, por lo tanto, no espera que algún lector ilustrado venga a reprocharle su falta de rigor histórico.

\section{Escribir contra Rosas}

La novela de Manso, como ya anticipamos, forma parte del corpus de narraciones escritas en el exilio por los opositores a Rosas, como Echeverría, Mármol, Sarmiento, Gorriti, entre otros, con los cuales comparte un imaginario común y un repertorio de escenas y personajes prototípicos, así como una retórica y una argumentación destinadas a probar la justicia de la causa antirrosista.

En un trabajo de consulta indispensable, Proyección del rosismo en la literatura argentina, Adolfo Prieto analiza los diferentes procedimientos a través de los cuales "desde que Rosas aparece en el panorama político, hacia 1820, su figura se incrusta en todas las corrientes de opinión, afecta en diversos planos la sensibilidad colectiva y se vuelve materia polémica inagotable"51. Particularmente, señala Prieto, el testimonio literario permite rastrear los pasos que convirtieron a este terrateniente de familia patricia en un "genio del mal", y preguntarse por "los elementos que intervinieron en este proceso transmutador" (loc. cit.).

Esta figura de poder, que domina la política argentina durante tres décadas (a partir de lo que se denominó "la anarquía del año 20") va acompañada en el imaginario popular por una serie de rasgos caracterizadores y de figuras que actúan como satélites de su persona: la esposa, Encarnación Ezcurra, la férrea "Heroína de la Federación"; la hija ${ }^{52}$, Manuelita, presentada como el ángel que intercede ante su padre por los opositores perseguidos; su cuñada María Josefa, acérrima enemiga de unitarios y federales desleales; los grotescos bufones Eusebio y Biguá; sus colaboradores más adictos, desde el edecán, el general Corvalán, hasta los jefes de la Mazorca, como Cuitiño, Salomón o Alen. Estos personajes serán quienes, entre 1830 y 1852, llenarán el escenario de "figuras familiares, de sobreentendidos, de consejas, de lugares comunes" 53 .

${ }^{51}$ Adolfo Prieto, Proyección del rosismo en la literatura argentina, Universidad del Litoral, Rosario, 1959, p. 11.

$52 \mathrm{El}$ hijo, Juan, es una figura ausente en la iconografía del rosismo.

53 A. PRIETO, op. cit., p. 26. 
La literatura opositora simplificó los rasgos de estos personajes, acuñando "tipos" que se convirtieron en paradigmas identificatorios del campo enemigo en la lucha entre las dos facciones. Así, la dulce Manuelita quedará inmortalizada en la memoria colectiva como la hija devota de un padre tiránico -sin que altere esta imagen congelada su eficaz participación como "agente diplomático y político" de Rosas, a partir de la muerte de doña Encarnación ${ }^{54}$; en cambio el leal Corvalán, de limpia trayectoria en las guerras de independencia, será convertido en una figura grotesca, una especie de viejo maniquí que se limita a vegetar sobre la tierra ${ }^{55}$.

A pesar de la amplísima producción de los opositores exiliados en diferentes países limítrofes -Bolivia, Brasil, y muy especialmente Chile y Uruguay- la literatura, señala Prieto,

no fue agente decisivo en el proceso político-social del rosismo; esta afirmación no excluye, sin embargo el reconocimiento de la enorme importancia que libros, folletos, hojas periódicas y versos memorizados tuvieron en cada una de las etapas de su gestación... Cabe asignarle a la literatura el papel de amplificador, deformador y mistificador de la realidad que le dio sustento... Tanto se borró el perfil humano de los actores, tanto se aventaron los odios y las pasiones recíprocas, que hacia el ocaso del drama ya levantaban estatura mítica muchos de los hombres y de las situaciones que jugaron el estricto episodio histórico ${ }^{56}$.

La cita ilumina el sentido de las producciones literarias de los exiliados antirrosistas -integrantes de la llamada "Generación del 37"- los cuales comparten un repertorio de figuras paradigmáticas - como los ya citados Corvalán, Manuelita, Cuitiño-; metáforas - Rosas en figura de Tigre o Minotauro-, cronotopos - la casa del dictador-e ideologemas - la causa unitaria identificada con el progreso y la civilización/la causa federal, con el atraso y la barbarie- que permiten leer su obra en una especie de continuum.

54 Cf. Carlos Ibarguren, Manuelita Rosas, $3^{\mathrm{a}}$ ed., Carlos y Roberto Nalé Eds., Buenos Aires, 1953, p. 30.

55 "Corbalán es un autómata viviente perfecto que repite lo que se le manda...; peleó sin entusiasmo ni valor, no huyó porque los otros no lo hicieron" (LMP, p. 119). En Amalia es "un viejecito de fisonomía enjuta, escuálida", de cuerpo contrahecho y vestido anticuadamente (Casa de las Américas, La Habana, 1976, p. 47).

56 A. Prieto, op. cit., p. 33; las cursivas son mías. 
El lector de este corpus no dejará de registrar un "aire de familia" entre las imagénes, metáforas y diversas formas de representación empleadas por Manso y las de sus contemporáneos Echeverría, Sarmiento, Mármol. Antes de entrar en las particularidades de cada uno, resulta conveniente, en primer lugar, recordar el mundo de relaciones, amistades, experiencias de vida que vinculan a estos intelectuales y que crean lazos más estrechos que el simple "aire de época" obviamente presente. La ideología compartida se expresa también por medio de un lenguaje común.

Echeverría es el maestro indiscutido de la generación, el viajero que abreva en París de las fuentes del Romanticismo, el que lo implanta tempranamente en el Río de la Plata. "El matadero", el primer cuento hispanoamericano, relata, como se recordará, la muerte de un joven unitario a manos de los carniceros federales, en un texto que inaugura la literatura argentina con la marca de la violencia. El cuento, supone la crítica, debió ser escrito en Buenos Aires (o en la campaña circundante) hacia 1838 y permaneció inédito hasta 1871, cuando lo publicó en la Revista del Río de la Plata su editor y amigo Juan María Gutiérrez.

No hay datos que permitan aventurar que Echeverría hubiera dado a conocer el cuento a sus amigos en el exilio de Montevideo. Lo que sí es evidente, en sus páginas y en las de Manso, es el sentir compartido por una clase atemorizada ante el populacho, de quien la separa un abismo económico, cultural y hasta lingüístico. Así, el joven unitario del "Matadero" encuentra un paralelo en el enfrentamiento de Rafael Martínez -un personaje secundario- con un grupo de mazorqueros (LMP, pp. 186 ss.). El patrón de belleza masculina con que se lo presenta - estilizada y casi femenina-, las formas solemnes de tratamiento ("seguid vuestro camino") y la valentía ante los adversarios lo equiparan con el anónimo personaje de Echeverría. A diferencia de éste, Martínez consigue burlar hábilmente a sus enemigos. Pero se trata de una salvación efímera, como revela la nota de la autora, ya que cuatro años más tarde será fusilado ( $L M P$, p. 186). El paradigma de Echeverría parece así inexcusable para estos héroes. Otro elemento en común está dado en la asociación de los protagonistas (unitario/Avellaneda) con una simbología religiosa -ambos vinculados con la figura del Cristo sufriente.

En el caso de Sarmiento, cabe recordar su estadía de dos meses en Río de Janeiro a principios de 1846, en viaje hacia su 
misión europea. En carta a Mitre desde esa ciudad (de 19 de febrero de 1846) hace grandes elogios del poeta Mármol que allí le es presentado; pero en el círculo de los jóvenes escritores argentinos no parece haber lugar para Juana Manso, que, recién casada, está a punto de embarcarse hacia Estados Unidos; su encuentro con Sarmiento tendrá lugar muchos años más tarde, en 1859. De todos modos, los ecos del Facundo, ese encendido panfleto contra Rosas publicado en Santiago de Chile un año antes de emprender su viaje, han llegado a todos los oídos unitarios. Algunos, como nuestro Valentín Alsina, subrayarán descuidos y exageraciones del autor, que por cierto nunca verá llegada la hora de enmendarlas; otros, como Juana Manso, compartirán el espíritu y las imágenes de este ensayo que adopta muchas veces los cánones de la ficción. El destino de un país que arranca a la deriva su vida independiente es visto como un misterio que no se resuelve por la razón sino por la mirada profunda e inspirada del genio del escritor o del ser que vuelve de ultratumba.

Otros elementos comunes nacen de saberes u opiniones ya instaladas en el "sentido común": la música gauchesca es para Manso "triste y monótona como desierto" (LMP, p. 17); para Sarmiento, "pesada, monótona, irregular" (Facundo, p. 106); Rosas será presentado - de acuerdo con la información general- como el paisano campechano, el mejor gaucho, el que por eso conquista las voluntades de la campaña- para orientarlos hacia el mal, de acuerdo con la visión de este grupo (cf. $L M P$, p. 17).

Pero con quien entabla Manso el vínculo más estrecho y continuado es con su paisano José Mármol (Buenos Aires, 18181871), con quien comparte los años de exilio en Montevideo primero, y después en Río de Janeiro. El prologuista de la edición definitiva de los Misterios orienta la atención del lector hacia la relación que existe entre esta novela y la de Mármol, enfatizando una amistad que prestigia, indirectamente, la obra literaria de una escritora menos valorada que su colega: "Su punto de vista es semejante al de Mármol, con quien mantuvo estrecha amistad intelectual" ( $L M P$, p. 5). Confirma esta relación la extensa carta de Mármol a su "querida amiga" que, desde su nuevo exilio en Río de Janeiro, expresa su disgusto por el Brasil y los brasileros - "de carácter superficial y degradados por su misma molicie”, producto de un régimen político monárquico y esclavista, coincide Mármol en la respuesta. La carta, fe- 
chada en Montevideo en mayo de 1842, atestigua una real camaradería tanto en el terreno político como literario:

He tenido el placer de recibir su carta de 7 de marzo, que conservaré siempre como el más bello testimonio de su feliz talento. En ella se percibe fácilmente el Espíritu contemplativo y melancólico que constituye el Carácter actual de la juventud argentina y que representa $\mathrm{V}$. tan sentidamente como lo hacen todos aquellos que son capaces de ponerse al frente de los instintos de su época. [Y más adelante]: ¿Cómo va la poesía? ¿Trabaja V. mucho? Su linda improvisación a la Campana me la he apropiado en cambio de la "despedida" que no quiere V. dejarme. Trabaje V. amiga mía, y mándeme, en lo posible, todo lo que haga ${ }^{57}$.

Entre los Misterios y Amalia la lectura descubre varios puntos de contacto, que van más allá de la temática común: ¿cuestión de influencias, de filiación, de visiones compartidas por los dos amigos?

La fecha establecida por Lewkowicz para la primera publicación de los Misterios (Río, 1852) así como las observaciones de la propia autora sobre el proceso de creación, hacen difícil sostener esta relación en términos de filiación absoluta, ya que Amalia, como se sabe, se publicó como folletín en 1851. Cabría pensar que, a su regreso a Brasil (1849) Manso puede haber intercambiado algunas ideas con Mármol sobre las novelas que ambos estaban escribiendo - las dos destinadas a aparecer como folletín, según la estrategia editorial de la época. Pero, mientras no se descubra correspondencia que corrobore este intercambio, sólo queda apelar al texto para señalar afinidades y divergencias.

Digamos, en primer lugar, que el repertorio de hechos y figuras de que echan mano los escritores antirrosistas tampoco es demasiado variado. Se trata de buscar un episodio, histórico o semihistórico, que dé cuenta de las crueldades y arbitrariedades del régimen rosista, para denunciarlo ante una Europa demasiado complaciente y lograr el apoyo para la causa de la oposición.

En este sentido, tanto Mármol como Manso apelan a episodios de un pasado muy reciente como eje de su trama narrativa: la frustrada huida de varios jóvenes unitarios en 1840 en Amalia; la, primero frustrada y luego exitosa, huida del unitario Valentín

57 Apud Velasco y Arias, op. cit., pp. 208-210. 
Alsina en 1838, en Los misterios del Plata. (Podría recordarse aquí que los dos futuros novelistas habían protagonizado sendas fugas de Buenos Aires, con mejor fortuna que sus personajes.)

Pero después de este punto de arranque en común, son patentes las diferencias: la novela de Mármol se enrola en los cánones del drama sentimental con elementos costumbristas y de novela de aventuras, sin que falten pinceladas de humor, a veces grotesco, a veces satírico. La novela de Manso, en cambio, se ciñe al episodio central para utilizarlo como eje de denuncia sobre una situación de represión general, a la vez que augurio de una deseada victoria sobre el Tirano (algo por cierto no difícil de hacer, ya que esta victoria tiene lugar durante la publicación de los Misterios).

Amalia se adscribe con mucho mayor rigor a los cánones del folletín: multitud de personajes, tramas intercaladas, suspenso, escenas de humor que aligeran la tensión dramática. Los misterios, en cambio, avanzan sin distracciones hacia su desenlace, con el agregado de pocos episodios ajenos a la trama central.

Uno de los pasajes donde la cercanía entre los dos textos resulta más patente es lo que, siguiendo a Bajtin, podemos llamar el cronotopo de la casa de Rosas. La casa de Rosas, cuya descripción -el afuera y el adentro- no casualmente ocupa los dos capítulos centrales de los Misterios, se constituye en ambas novelas en un espacio que parece condensar los sentimientos de fascinación, temor y repulsión que su figura despierta entre sus opositores $^{58}$.

Rosas vivió en la gran casona colonial de sus suegros, los Ezcurra -donde tenía también su despacho de gobierno- hasta que, en los últimos años de su gobierno, trasladó su residencia a la igualmente célebre quinta de Palermo. Situada a pocas cuadras de la Plaza de Mayo, en la zona más céntrica y comercial de la ciudad, habitada por la mayor parte de las familias

58 DAVID ViÑas, "Mármol y los dos ojos del romanticismo", Literatura argentina y realidad política. De los jacobinos porteños a la bohemia anarquista, Sudamericana, Buenos Aires, 1995, confronta la descripción de la casa "europea" de la civilizada Amalia con la sórdida casona colonial donde vive el bárbaro Rosas. Ya fuera de la ficción, el general Paz evoca en sus Memorias el ambiente que reinaba en las cercanías: "Es imponderable el silencio y la lobreguez de aquella calle"; y en la casa: "Un gran patio sombrío y desierto en que reinaba el más profundo silencio es lo único que vi” (apud José Luis Busaniche, Rosas visto por sus contemporáneos, Hispamérica, Buenos Aires, 1985, p. 69). 
patricias, la imagen que plasman las novelas no se corresponde con ese referente, sino que condensa un símbolo: se trata de la Mansión del Mal, guardada por feroces cancerberos ${ }^{59}$ y reducto de hechos sanguinarios o aberrantes. Para acentuar con tintes de novela gótica lo sombrío de este dominio, Manso inventa a la chata casona colonial un "altísimo mirador que domina a la ciudad entera" y que es "la habitación habitual del dictador" ( $L M P$, p. 102). El edificio se anima, en medio de la ciudad silenciosa y paralizada por el terror, y obtiene poderes terribles: "Aquella casa, rodeada siempre de asesinos y bandidos, parece pronta a arrojar de sí puñales y proyectiles por todos los ángulos de la población" (LMP, p. 106). Mármol, por su parte, la define con una imagen imborrable: "la casa del Atila pampa"60.

La escena en la que Rosas hace su aparición en ambas novelas -la hora de la comida- tiene lugar en plena noche, lo cual, más allá del dato histórico ${ }^{61}$, dota de un nuevo elemento melodramático una costumbre cotidiana. Es que aquí la escena de la comida dará lugar a presentar al personaje en sus facetas más degradadas - las burlas soeces contra sus bufones, en ambos relatos-, o sanguinarias -su manifiesta alegría por el degüello de unos fugitivos, en Amalia.

Si la coincidencia entre ambas novelas en la presentación del lugar y la escena elegida es llamativa, no deja de resultar también significativo, en este caso por oposición, el tratamiento de una figura proverbial en la iconografía (anti)rosista: su hija Manuela.

En Amalia, el enojoso episodio suscitado durante la cena (Rosas azuza al bufón para que bese a la joven) es utilizado por Mármol para presentar a Manuela como una víctima de las arbitrariedades paternas, pero a la vez una mujer inteligente y sensible que no cierra los ojos ante las atrocidades de su entorno. En Los misterios del Plata, en cambio, Manuela es una figura

59 Tanto Manso como Mármol describen con rasgos siniestros la custodia de Rosas, formada por gauchos "de rostro infernal" (LMP, p. 104) e indios pampas "como otros tantos perros de presa que estuvieran velando" (Amalia, p. 48).

60 Así la denomina en el ensayo biográfico dedicado a "Manuela Rosas", de 1850 (Asesinato del Sr. Dr. D. Florencio Varela; Manuela Rosas, ed. y pról. J. C. Ghiano, Casa Pardo, Buenos Aires, 1972), que le servirá como base para crear a su personaje en Amalia, de 1851.

61 Todos los cronistas de la época hacen referencia a la costumbre de Rosas de trabajar durante toda la noche; cf. J. L. BusAniche, op. cit. 
fugaz, que al iniciarse la escena se aleja "dando las buenas noches, hacia otros pisos de la casa” (p. 109). No tiene rostro ni voz que le permitan asumir una identidad propia (ni obtener un atenuante a su posible culpa) dentro de esta atmósfera de "barbarie y salvajismo" (p. 106). Es que Manuela ya está condenada por la autora como "hija querida y digna de S.E. el Ilustre Restaurador de las Leyes". Cuando vuelva a aparecer en la novela será durante un desfile, en medio del populacho, encabezando un grupo de hombres a caballo, vestida ella misma "con el traje de los gauchos y enormes espuelas"; es decir, consustanciada con la barbarie del régimen. Y la autora corrobora en nota al pie: "Este medio ha sido empleado muchas veces" (p. 167). No hay en Manso concesiones al mito de Manuela como "el ángel de la Federación". Y es especialmente severa también su condena a las cuatro señoras federales que, en uno de los actos cívicos en homenaje al Restaurador, arrastran el carruaje que conduce un retrato de Rosas. Sus nombres, acota, debe "conservar [los] la historia con curiosidad". Pero, por si la Historia se distrae o pierde la memoria, ella misma los incluye en una nota al pie (p. 168) ${ }^{62}$.

\section{Historia y ficción}

Los "episodios históricos de la época de Rosas", como reza el subtítulo de la novela, se centran en un hecho ocurrido en 1835 o $1837^{63}$. Cuando Rosas reasume en 1835 el poder, con la suma de las facultades extraordinarias, hotiliza al doctor Valentín Alsina, uno de los más destacados "cuadros" del partido unitario. Alsina huye con su esposa y su hijo Adolfo hacia la

62 Se trata de M. Josefa Ezcurra, cuñada de Rosas; la esposa del Ministro de Relaciones Exteriores, Felipe Arana, la esposa del General Alvear y la del General Guido. La nota acusadora se mantendrá en las ediciones posteriores.

${ }^{63}$ La biografía más antigua de Adolfo Alsina -la de Enrique Sánchez, Biografía del Dr. D. Adolfo Alsina. Recopilación de sus discursos y escritos, Buenos Aires, 1878-, en la cual se apoyan todas las posteriores que he consultado, señala la fecha de 1835 para el episodio ficcionalizado por Manso. Sin embargo, parece acertada la corrección propuesta por quien asesora al editor de la novela situando el hecho un par de años más tarde $(L M P$, p. 213). Resulta verosímil que los opositores a Rosas, vuelto al poder en 1835, esperasen un tiempo el desarrollo de los acontecimientos antes de optar por el exilio. 
provincia de Corrientes -relativamente autónoma de las decisiones del jefe de la Confederación Argentina- pero en el camino es detenido y devuelto a Buenos Aires, donde se lo confina en el pontón "Sarandî"64. Gracias a su mujer, Antonia Maza -hija de don Manuel Maza, hasta entonces partidario y amigo de Rosas-, se organiza la fuga. Alsina logra escapar con toda la familia a Montevideo, donde se constituye en una de las principales cabezas de la oposición.

El episodio histórico servirá de base -con algunas modificaciones - a la novela. La autora introduce una variante en la fecha y ubica la acción en 1838, sin que resulte muy clara la razón de este cambio que no se preocupa por fundamentar, a pesar de sus reiteradas protestas de apego a la verdad histórica ${ }^{65}$. Para explicar esta alteración de la cronología podría plantearse como hipótesis que la autora haya elegido para enmarcar su novela uno de los años más dramáticos del período rosista, que quedó grabado con especial fuerza en la memoria colectiva. En el plano exterior, se inicia el primer bloqueo anglofrancés, que trae graves consecuencias para la política y la economía del régimen. En el plano interno, el año comienza con la muerte del litógrafo francés Hipólito Bacle, a quien Rosas encarceló por sospechar - con razones bastante fundadas-que era espía y falsificador; su muerte será uno de los argumentos esgrimidos por Francia para justificar el bloqueo al puerto de Buenos Aires. Ese mismo año fallece Encarnación Ezcurra, esposa del Restaurador y su más fiel y combativa aliada. Todos estos factores agravan el clima de persecución a los opositores.

Por otra parte, la ubicación temporal de la novela, presentada en el enunciado inicial ("Era una hermosa tarde de otoño de 1838") podría leerse como un homenaje al modelo, dado que la novela de Sue comienza en el mismo año y con una construcción verbal similar, si bien en este caso el inicio se orienta a subrayar el clima lóbrego del submundo parisiense elegido

${ }^{64}$ Un pontón -recordemos- es "un buque viejo que, anclado de firme en los puertos, sirve de almacén, de hospital o de depósito de prisioneros" (DRAE, s.v.). En la Argentina volvió a echarse mano de este tipo de cárcel de "máxima seguridad" en 1976, para confinar a presos políticos "distinguidos".

65 "Son horribles estos hechos -se refiere a las solemnes procesiones en homenaje a Rosas- pero desgraciadamente ciertos y verdaderos porque los hemos presenciado" (LMP, p. 122). Más adelante: "Esto es histórico y cuanto se lea a este respecto no da sino una débil idea de cuanto ha sucedido" (p. 173). 
como escenario: "Al anochecer de un día frío y lluvioso de octubre de $1838 . . . " 66$.

Una segunda modificación respecto del hecho histórico resulta mucho más significativa. En una de las múltiples notas de la autora se explica que el "héroe de este romance histórico es don Valentín Alsina", pero que se le dará el nombre de "Marco Avellaneda... para perpetuar al mártir de Tucumán” (p. 24). La figura de este joven político, gobernador de su provincia, que poco tiempo atrás fuera derrotado y ejecutado por la facción federal, se constituyó en uno de los iconos del martirologio unitario, hasta lograr la "estatura mítica" señalada por Prieto $^{67}$; de allí el -curioso- homenaje que se le rinde, convirtiéndolo en personaje de folletín.

La autora argumenta, además, que por publicar la novela antes de la caída de Rosas, debe optar por el cambio de nombre. Sin embargo, el recurso parece poco eficaz, dado que la referencia al personaje real resulta transparente; su fuga había tenido gran difusión en el restringido ámbito de la sociedad rioplatense, y para pocos era un secreto el sujeto real que se escondía tras el tenue seudónimo.

En lo demás, la trama de la novela se apega estrechamente al hecho histórico. Alsina/Avellaneda y su familia se dirigen en una balandra hacia Corrientes, pero, traicionados por el capitán, caen prisioneros y son llevados a Buenos Aires. Allí la esposa de Avellaneda mueve todos los resortes a su alcance para salvarlo. Disfrazada de militar, sube al pontón, con el niño escondido entre los pliegues de la capa y consigue que la ballenera que debe conducir al prisionero hacia su cárcel definitiva en el fuerte de Buenos Aires ponga proa hacia Montevideo. La Conclusión (como se recordará, un añadido del editor) expone los destinos de los perso-

66 Cito por la edición de Sopena, Barcelona, 1935, 2 ts. Se trata, por lo demás, de un inicio muy frecuente en la novela popular del xix, destinado a situar desde el comienzo al lector en el aquí y ahora de la historia.

67 A. Prieto, op. cit., p. 33. El impacto de esta muerte no se atenúa con los años. En una fecha muy posterior ( $c a$. 1870) al hablar de la época de Rosas en su Compendio de historia, Juana Manso dedica al episodio un párrafo de tintes melodramáticos: "Cada provincia tuvo su mártir; pero entre todos descuella el Dr. D. Marcos Avellaneda, cortado en cuartos que fueron clavados en postes por los caminos, y su inteligente cabeza en la misma plaza de Tucumán, frente a la morada de su esposa y de sus hijos pequeñitos" (p. 242). La autora llegaría a ver a uno de esos hijos, Nicolás, convertido en Presidente de la República (1874-1880). 
najes secundarios, sin que el nuevo narrador parezca reparar en la cruel ironía de esos destinos. El doctor Avellaneda se convierte en una figura reconocida de la oposición en Montevideo, acompañado y fortalecido "por la entereza de su fiel consorte Adelaida" (p. 219); en cambio, los heroicos gauchos Miguel y Simón, a quienes les debe la vida, han muerto "brava aunque anónimamente -como perece siempre el soldado" en diversos combates contra las tropas aliadas a Rosas.

En torno a la trama central se organiza una red de personajes y situaciones que contribuye a presentar la imagen de una sociedad en claroscuro: por un lado, los hombres valerosos, bienintencionados, enemigos de Rosas y perseguidos por sus secuaces; por otro, los seres feroces, ignorantes, abyectos, que rodean al tirano y ejecutan sus órdenes apelando a la traición o a la fuerza. Todo este mundo está presentado de una manera simplista donde el narrador tipifica con adjetivos maniqueos a los personajes o reparte los atributos físicos de acuerdo con la mayor o menor virtud que posee cada uno. Así, Ramón Maza - hermano de Adelaidatiene "una estatura perfecta, rostro oval, noble, varonil y bien delineado... frente blanca como el alabastro... boca punzó y húmeda", etc. (p. 128). En cambio, el mazorquero Salomón "es viejo y creemos que desciende de la unión entre indígena y mulato. Tiene el color y el cabello de los pampas, la boca gruesa y la soberbia natural de los mestizos..." (p. 135).

La acción se detiene en numerosos pasajes para que "la autora" señale una serie de "hechos vergonzosos a la execración de la América y del mundo" (p. 204): así, la delación de los sirvientes en las casas patricias; o la ciega veneración de las masas inferiores hacia el dictador: "El pueblo bajo, compuesto en buena parte por negros y mulatos, está conforme con Rosas como lo estuvo en la Roma de los césares con Claudio, con Nerón o con Calígula" (p. 204).

El relato de la fuga, finalmente, desemboca en la cristalización del objetivo planeado por la "heroica mujer", después de una serie de preparativos minuciosamente descritos, y con un estilo más cercano a la crónica que a la ficción (cap. 39).

\section{La trama histórica: intenciones y significados}

Frente a toda novela histórica, el lector puede preguntarse por qué el autor ha elegido determinado episodio para recrearlo 
en los marcos de la ficción. En el caso de Los misterios del Plata son varios los elementos que justifican esta elección. En primer lugar, para la autora son evidentes los méritos de la historia elegida para perdurar a través de las páginas de una novela: "Aquella mujer [Adelaida] iba a ser la heroína de uno de los episodios más curiosos que relatará el futuro historiador de esta época de singular anarquía” (p. 212)

En primer lugar, justifica esta elección el hecho de que el episodio tiene, excepcionalmente, un "final feliz", que el texto se ocupa de subrayar. Por primera vez el "tirano" pierde a su presa, y, también por primera vez, el motor de este desenlace afortunado es una mujer: "Estaba de Dios que Rosas no saldría esta vez con su gusto. Una mujer habría de deshacer todos sus planes y esa mujer fue Adelaida, la esposa del doctor Avellaneda" (p. 202). A Adelaida se la compara con Juana de Arco por su fuerza y su heroísmo, aunque ella será más afortunada que su modelo:

Si Juana de Arco se inspiró en la divinidad de su misión y la realizó, Adelaida buscó fuerzas, astucias y medios en el amor de su cariño y en el cariño de su hijo a quien no concebía que tuviera que criar huérfano, y, como la heroína francesa, esta heroína esposa salió triunfante en su empresa, sin pagar con la existencia la temeridad de su propósito (LMP, p. 202).

Puede observarse la simplificación operada al equiparar el origen de la fuerza que mueve a ambas heroínas: la misión divina que indujera a liberar al pueblo francés queda reducida aquí a la categoría de los valores de la familia burguesa. L. Zucotti analiza lúcidamente este reduccionismo, como un rasgo que diferencia los relatos de las escritoras del corpus de la literatura antirrosista de los de sus pares masculinos:

Si los escritores hacen del relato de la estrategia militar o política el eje de sus textos, las escritoras narran permanentemente la formulación de estrategias domésticas: cómo salvar a un padre, un hermano, un esposo o un amante (casi siempre personajes públicos importantes) de un enemigo, la cárcel o la muerte se transforma en la vuelta de tuerca por la cual los personajes femeninos intervienen en los enfrentamientos públicos a través de mecanismos eficaces pero poco ortodoxos 68 .

${ }^{68}$ En "Los misterios del Plata: el fracaso de...", p. 387. 
En otro plano, la elección del episodio vivido por la familia Alsina tiene una clara intención política. Valentín Alsina es el jefe reconocido del grupo unitario exiliado en Montevideo, al cual se adhieren la autora y su familia. El texto literario se convierte así en homenaje partidista, explicitado abiertamente en nota a los lectores al cerrar la publicación de Os Mysterios en 1852:

Como sabeis, leitoras, depois da quéda do tyranno, Alsina foi chamado ao ministerio. Assim devia de ser: hoje pediu a sua demissao e se retirou a vida privada; è a ultima prova que esperavamos da virtude do nosso heroe, a quem mais ainda uma vez prestamos nossa homenagem de admiraçao e respetto ${ }^{69}$.

Agreguemos que, a la luz de la historia futura, cobrará relieve la figura del niño, Adolfo - que conserva el nombre real en la ficción-el cual será uno de los políticos más relevantes de las décadas de los años sesenta y setenta ${ }^{70}$. Está claro que la autora no podía augurar ese destino al publicar la novela en 1852. Pero cuando la reedita en El Inválido Argentino (1869), Adolfo Alsina, dotado de un fuerte liderazgo sobre el pueblo de Buenos Aires, ya ha llegado a la vicepresidencia bajo el gobierno de Sarmiento. Es evidente pues el objetivo político que subyace en el texto novelesco, con su doble homenaje al padre y al hijo.

Por último, el episodio elegido como nudo de la ficción cobra una particular dimensión si se lo lee en la perspectiva de un futuro deseado. A diferencia de otros textos de igual filiación ideológica -"El matadero", Amalia, algunos cuentos de Gorriti, como "El guante negro" o "La hija del mashorquero"71_ donde la tragedia sella el destino de los personajes que se atreven a enfrentar al tirano, aquí Rosas se verá burlado. Junto con el valor de la "heroica mujer", se destacan las cualidades de los personajes de distintos niveles sociales que colaboran en el éxito de la empresa: gauchos incultos pero de noble corazón, servidores fieles, patriotas honrados. Todo ello apunta a persuadir al lec-

${ }^{69}$ Citado por Lewkowicz, op. cit., p. 217.

${ }^{70} \mathrm{Su}$ segura carrera hacia la presidencia de la República se verá cortada por una muerte prematura, en 1877.

${ }^{71}$ Juana Manuela Gorriti, Sueños y realidades, Biblioteca La Nación, Buenos Aires, 1907, 2 ts. 
tor de que la tiranía no ha logrado seducir y corromper por completo a la población: un elemento que pide ser leído como augurio promisorio.

Todo relato implica la necesidad de buscar una organización en la masa informe de acontecimientos que constituye la vida. Al narrar se organizan los hechos en una secuencia que les confiere un principio de orden. Pero la búsqueda de orden es, en definitiva, una búsqueda de significado. A la sucesión de hechos múltiples, fragmentarios, heterogéneos, que constituyen la dinámica de la vida, se les pide un objetivo, una finalidad que dé sentido. Así, la novela histórica -como queda patente en el objeto de nuestro estudio- selecciona los distintos acontecimientos que, organizados en la ficción, se iluminan unos a otros y revelan una causalidad no siempre demostrable en los hechos de la "realidad".

$\mathrm{Al}$ referirse a las relaciones entre el discurso de la historia y el de la ficción, Hayden White subraya la frecuencia con que "la narratividad, bien ficticia o real, presupone la existencia de un sistema legal contra o a favor del cual pudieran producirse los agentes típicos de un relato"72. De allí la importancia que adquieren temas que tienen que ver con la ley, el orden, la autoridad, que funcionan como vertebradores de la mayor parte de los textos sustantivos de la narrativa hispanoamericana. White agrega:

Si toda narración plenamente realizada... es una especie de alegoría, apunta a una moraleja o dota a los acontecimientos, reales o imaginarios, de una significación que no poseen como mera secuencia, parece posible llegar a la conclusión de que toda narrativa histórica tiene como finalidad latente o manifiesta el deseo de moralizar sobre los acontecimientos de que trata (ibid., p. 29; las cursivas son mías).

Más allá del objetivo explicitado por la autora al comienzo de su relato -develar los misterios de un sistema político- el desarrollo del texto se va abriendo a nuevas perspectivas. Al ficcionalizar una realidad pasada - un episodio menor en sí mismo, en el caso elegido-se pretende convertirla en paradigma, en modelo y augurio. Lo que ocurrió es figura de lo que ven-

72 El contenido de la forma. Narrativa, discurso y representación histórica, Paidós, Buenos Aires, 1992. 
drá. De este modo, el texto literario aspira a convertirse no sólo en espejo de la realidad sino en instrumento de la creación de un nuevo orden y una nueva legalidad.

\section{CONCLUSIÓN}

Obstinada en su vocación por aparecer ante el mundo, Los misterios del Plata acepta geografías y lenguas diversas, tolera manos que la completan, corrigen o interpretan a su antojo, aparece en soportes tan diversos como un periódico de guerra o una colección donde convive con Tarzán.

Panfletaria, ingenua, mal traducida -o mal escrita- funciona como blanco de éstas y otras muchas críticas (merecidas) que se le pueden formular. Sin embargo, constituye en sí misma una empresa que no acepta reducirse a un simple juicio estético. Adquiere significado al insertarse en el contexto en el que fue imaginada, escrita, refundida y vuelta a publicar. Tal vez por eso, a pesar de lo que dijera don Ricardo, la obra de Juana Manso sigue viviendo tanto como su nombre.

Margarita Pierini Universidad de Quilmes 